\title{
Comparative study of multi-station method and Hershfield's approaches for PMP determination (case study: Northeast of Iran)
}

\author{
Mohammad Tajbakhsh ${ }^{1} \cdot$ Nadhir Al-Ansari ${ }^{2}$
}

Received: 1 June 2017 / Accepted: 28 September 2018

(c) Springer Nature Switzerland AG 2018

\begin{abstract}
The maximum daily rainfall values for 36 homogeneous stations in the northeast of Iran were adopted to estimate the appropriate Probable annual Maximum Precipitation 1-day precipitation $\left(\mathrm{PMP}_{24}\right)$ values. $\mathrm{PMP}_{24}$ was found as 128.2-284.2, 62.7-160.2 and $124 \mathrm{~mm}$ for Hershfield 1, Hershfield 2 and multi-station approach, respectively. The ratio of $\mathrm{PMP}_{24}$ to the highest observed 1-day rainfall was consistent for the second approach of Hershfield. It was in harmony with the multi-station method, but varied widely for Hershfield 1. This may be the result of different record length effect on Hershfield 1 approach. Finally, the map of $\mathrm{PMP}_{24}$ isochrones was prepared for the second approach of Hershfield for over northeast of Iran.
\end{abstract}

Keywords Probable maximum precipitation $\cdot$ Hershfield $\cdot$ Multi-station $\cdot$ Northeast of Iran

\section{Introduction}

Estimates of probable maximum precipitation (PMP) have been used for many years to derive a "maximum" loading for designs of high hazard infrastructure such as dams and nuclear power plant structures (Prasad et al. 2011; Nathan et al. 2016). The PMP is most commonly used to derive an extreme flood using an appropriate model of the rainfall-runoff process (Federal Energy Regulatory Commission 2001), or it can be used to assess the risk of direct flooding on critical infrastructure due to localised rainfall (Hufman et al. 2014).

World meteorological organization (WMO) defined PMP as the greatest depth of precipitation for a given duration which is meteorologically possible over a given station or a specified area (WMO 1986). There are two main methods, including hydro meteorological and statistical approaches to calculate PMP. The second method is more useful when

Mohammad Tajbakhsh

tajbakhsh_md@yahoo.com

Nadhir Al-Ansari

nadhir.alansari@ltu.se

1 Regional Water Authority, Zan Blvd., Kermanshah, 6714799669, Iran

2 Department of Civil, Environmental and Natural Resources Engineering, Luleå University of Technology, Luleå, 97187 Luleå, Sweden meteorological data such as dew point, temperature, and wind speed are not available, but it requires a large amount of rainfall data.

Hershfield was a pioneer who developed a statistical method for estimating PMP values for small areas around the world. In this method, series of maximum annual daily rainfalls at an observation point are required, yet the partial duration series (Ghahraman and Khalili 2004) may be an alternative. He assumed the frequency factor $\left(K_{\mathrm{m}}\right)$ is equal to 15 , but Koutsoyainnis (1999) showed 15 for $K_{\mathrm{m}}$ is starter of a return period equal to 6000 years, which is not in harmony to PMP definition (Koutsoyainnis 1999). In 1986, WMO modified the Hershfield method and introduced the record length, and the maximum value observed for the correction of the $K_{\mathrm{m}}$.

In 1997, Eliasson presented multi-station method by applying the annual maximum 1-day precipitation $\left(\mathrm{P}_{24}\right)$ in the United States of America and Iceland (Eliasson 1997). This approach is based on Gumbel type 1 and its derived distributions (EV1). Since PMP can occur at every point within a homogenous region, this method is based on a combination of data from all stations in such a region. In multi-station method, PMP is less affected by data length and the highest values. Independency of $P_{24}$ in different stations is the base of the multi-station method. In dry regions, more than $30 \mathrm{~km}$ is the suggested average distance between stations (Buishand 1984). 
Desa et al. (2001) and Desa and Rakhecha (2007) introduced a new approach to the Hershfield method. They considered the maximum value of observed rainfall, which caused a severe decrease in $K_{\mathrm{m}}$. In Iran, Ghahreman used this method over Atrak watershed (Ghahreman 2008).

The moisture maximization approach has a simple technique for controlling the risk of overestimating PMP where the maximization ratio is limited by an upper bound. The upper bound limit depends on storm records and watershed characteristics (Rouhani and Leconte 2016). Rouhani and Leconte (2016) proposed an approach to estimate the maximization ratio which does not impose an upper limit. Their approach, was based on constructing annual maximum precipitable water time series with precipitable water values for which atmospheric variables are similar to the original event to be maximized. Results showed that maximization ratio values were lower than the proposed upper bound value in the province of Quebec, Canada. In comparison to the approach using an upper bound, the proposed approach reduced the PMPs in the study area by $11 \%$ (Rouhani and Leconte 2016).

To understand how PMP may respond to projected future climate forcings, Rastogi et al. (2017) used a physics-based numerical weather simulation model over the AlabamaCoosa-Tallapoosa River Basin in the southeastern United States. Results showed that atmospheric warming could be one important factor controlling the increase in PMP (Rastogi et al. 2017).

PMP in Barcelona (Spain) was estimated for durations ranging from $5 \mathrm{~min}$ to $30 \mathrm{~h}$ by Casas et al. (2011). Two different techniques were used: the Hershfield method, and a physical method based on the maximization of actual storms. The PMP values obtained using the two techniques were very similar. In both cases, the increasing behavior of the PMP with duration was found, with the increase especially notable for the durations $2-9 \mathrm{~h}$, and not significant from $12 \mathrm{~h}$ on up (Casas et al. 2011).

Climate change effects on PMP were analyzed by Kunkel et al. (2013). Climate model simulations indicated a significant future increase in water vapor concentrations. The changes in maximum values for the continental United States were approximately $20-30 \%$ by $2071-2100$. The authors concluded that PMP values would increase in the future due to higher levels of atmospheric moisture content and as a result of higher levels of moisture transport into storms.

The purpose of this research is to carry out a study on the estimation of PMP for a 24-h duration using multi-station method and two approaches of Hershfield technique for stations in the northeast of Iran and to select the most appropriate method.

\section{Study area and data used}

The need for the development of water resources has become a considerable importance in the northeast of Iran with a view to ensure sufficient potable and industrial water supplies, providing irrigation for food production and flood control. The study area, with more than $60,000 \mathrm{~km}^{2}$ areas, is located in the northeast of Iran. The rivers within this area are run either outside the Iranian borders or drain into the interior deserts. This watershed is bordered in the north by Turkmenistan, in the northwest by Semnan and Golestan provinces, and in the west, east and south by Khorasan Razavi province (Fig. 1). The characteristics of the stations are given in Table 1. The data record ranges from 13 to 48 years. The highest station is Marashk $(1870 \mathrm{~m})$ and the lowest one is Hatam Ghale $(490 \mathrm{~m})$. The average annual relative humidity and the annual average rainfall (for 30 years)
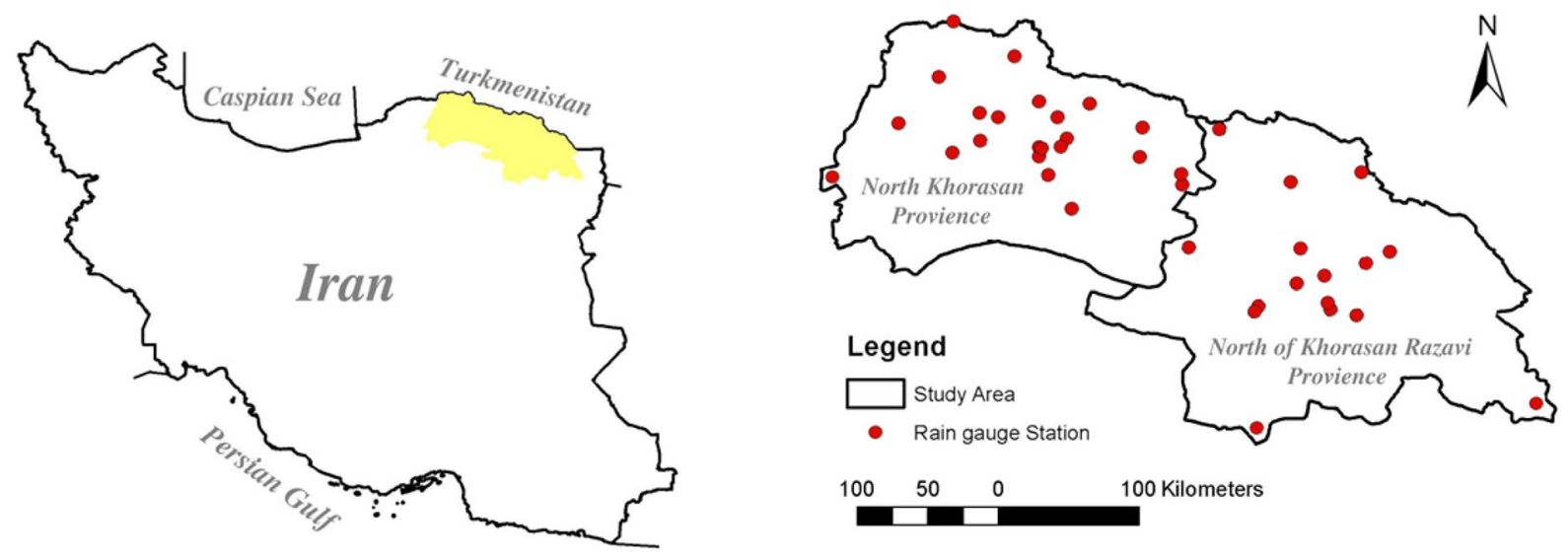

Fig. 1 Location map of the study area 
Table 1 List of stations within the study area

\begin{tabular}{|c|c|c|c|c|c|c|c|c|c|}
\hline \multirow[t]{2}{*}{ Number } & \multirow[t]{2}{*}{ Station name } & \multicolumn{3}{|c|}{ Geographic characteristics } & \multicolumn{5}{|c|}{ Station parameters } \\
\hline & & Latitude & Longitude & Height & $N$ & $P_{4}$ & $\bar{P}_{24}$ & $S$ & $C_{\mathrm{V}}$ \\
\hline 1 & Aghmazar & $37-41-32$ & $56-55-10$ & 580 & 30 & 50 & 25.1 & 9.36 & 0.37 \\
\hline$* 2$ & Radkan & $36-48-23$ & $59-0-30$ & 1210 & 28 & 52 & 24.7 & 7.65 & 0.30 \\
\hline 3 & Dahaneh-ye-Akhlamad & $36-36-00$ & $58-57-0$ & 1460 & 26 & 58 & 25.8 & 10.27 & 0.39 \\
\hline 4 & Ali Mohammad & $37-45-00$ & $57-37-28$ & 1260 & 30 & 62 & 28.2 & 10.71 & 0.37 \\
\hline 5 & Ardak & $36-43-47$ & $59-23-32$ & 1310 & 26 & 49 & 23.3 & 7.49 & 0.31 \\
\hline 6 & Asadli & $37-17-37$ & $57-21-33$ & 1800 & 16 & 56 & 36.1 & 12.27 & 0.33 \\
\hline 7 & Baba Aman & $37-28-40$ & $57-26-19$ & 1020 & 28 & 39 & 25.1 & 7.52 & 0.34 \\
\hline 8 & Barbar Qaleh & $37-28-23$ & $57-18-00$ & 1070 & 33 & 50 & 24.2 & 9.61 & 0.39 \\
\hline 9 & Bar-Aryeh & $36-27-34$ & $58-42-18$ & 1560 & 48 & 55 & 32.6 & 10.71 & 0.32 \\
\hline 10 & Barezoo & $37-35-55$ & $57-57-48$ & 1400 & 31 & 50 & 22.8 & 10.0 & 0.43 \\
\hline 11 & Besh Ghardash & $37-24-50$ & $57-17-58$ & 1160 & 17 & 35 & 22.7 & 6.90 & 0.30 \\
\hline 12 & Qareh Qanloo(Bahar) & $38-16-42$ & $56-45-20$ & 840 & 20 & 60 & 24.5 & 11.33 & 0.45 \\
\hline 13 & Esfarayen & $37-04-44$ & $57-30-40$ & 1210 & 29 & 47 & 28.3 & 9.44 & 0.33 \\
\hline 14 & Bojnord & $37-28-00$ & $57-19-00$ & 1091 & 27 & 41 & 24.4 & 8.18 & 0.33 \\
\hline 15 & Chenaran & $36-38-56$ & $59-07-36$ & 1170 & 15 & 49 & 21.1 & 10.12 & 0.46 \\
\hline$* 16$ & Dolat-Abad & $36-26-17$ & $59-10-00$ & 1510 & 27 & 42 & 24.3 & 7.21 & 0.29 \\
\hline 17 & Darkesh & $37-26-12$ & $56-45-00$ & 1060 & 30 & 47 & 32.9 & 7.51 & 0.22 \\
\hline 18 & Farooj & $37-14-00$ & $58-13-00$ & 1200 & 30 & 40 & 20.6 & 7.46 & 0.35 \\
\hline 19 & Garmkhan & $37-31-45$ & $57-28-38$ & 920 & 30 & 45 & 27.7 & 8.14 & 0.29 \\
\hline 20 & Ghadir Abad & $36-48-19$ & $58-58-22$ & 1175 & 13 & 10 & 19.8 & 5.77 & 0.28 \\
\hline 21 & Gholaman & $38-03-23$ & $57-08-39$ & 1240 & 13 & 57 & 29.7 & 11.37 & 0.37 \\
\hline 22 & Qezelqan & $37-39-52$ & $57-25-12$ & 1040 & 25 & 61 & 26.1 & 12.67 & 0.47 \\
\hline 23 & Golmakan & $36-28-48$ & 59-09-00 & 1450 & 32 & 41 & 25.3 & 7.68 & 0.30 \\
\hline 24 & Hatam Ghale & $37-18-40$ & $59-22-00$ & 490 & 34 & 45 & 22.8 & 9.55 & 0.43 \\
\hline 25 & Hesseh Gah & $37-39-23$ & $57-01-55$ & 620 & 19 & 35 & 25.4 & 5.91 & 0.23 \\
\hline$* 26$ & Incheh-Olya & $37-37-29$ & $56-24-14$ & 770 & 25 & 26 & 17.2 & 5.26 & 0.30 \\
\hline 27 & Jahan Abad & $37-18-11$ & $58-12-34$ & 1185 & 23 & 50 & 25.3 & 9.04 & 0.35 \\
\hline 28 & Kabkan & $37-15-00$ & $58-54-37$ & 1435 & 21 & 30 & 23.8 & 5.25 & 0.22 \\
\hline 29 & Khartoot & $37-55-24$ & $56-39-40$ & 695 & 30 & 19 & 28.9 & 7.37 & 0.25 \\
\hline 30 & Marashk & $36-49-12$ & $59-32-48$ & 1870 & 20 & 58 & 26.4 & 10.86 & 0.40 \\
\hline 31 & Chaman Bid & $37-28-40$ & $57-26-19$ & 1020 & 30 & 60 & 25.1 & 7.52 & 0.34 \\
\hline 32 & Sar Asiab & $36-24-00$ & $59-20-00$ & 1270 & 21 & 47 & 24.3 & 8.01 & 0.32 \\
\hline 33 & Se Yek Ab & $37-24-39$ & $57-56-49$ & 1110 & 31 & 46 & 24.9 & 8.61 & 0.34 \\
\hline 34 & Shamkhal & $37-35-21$ & $58-27-12$ & 1495 & 26 & 53 & 28.0 & 10.21 & 0.36 \\
\hline 35 & Shir Abad & $37-30-56$ & $56-55-30$ & 860 & 31 & 63 & 35.6 & 17.18 & 0.47 \\
\hline 36 & Taghun & $36-25-27$ & $58-40-50$ & 1495 & 28 & 50 & 27.5 & 7.56 & 0.27 \\
\hline 37 & Yangajeh & $36-49-52$ & $58-15-40$ & 1680 & 24 & 58 & 34.2 & 11.24 & 0.32 \\
\hline 38 & Dar Band & 37-36-01 & $56-59-13$ & 700 & 30 & 41 & 23.9 & 7.67 & 0.32 \\
\hline 39 & Qatlish & $37-46-00$ & $57-18-04$ & 980 & 31 & 45 & 20.6 & 8.38 & 0.41 \\
\hline
\end{tabular}

$N$ data length (years), $P_{24}$ observed 1 day highest rainfall value $(\mathrm{mm}), \bar{P}_{24}$ mean observed 1 day highest rainfall value (mm), $S$ standard deviation, $C_{V}$ Coefficient of variation $\left(C_{V}=S / \bar{P}_{24}\right)$

*Heterogeneous stations by Mann-Kendall rank test are about $55.6 \%$ and $270 \mathrm{~mm}$, respectively, indicating dry weather.

\section{Methodology}

\section{Homogeneity of the data series}

The use of longer series in the estimation of PMP, is only valid if they show no long-term changes in their behavior 
(Desa et al. 2001). To investigate such inhomogeneities, in the annual maximum rainfall series for 39 stations, non-parametric Mann-Kendall rank test was applied. The statistic is computed from $\tau=\left\{4 \sum n_{i} /[N(N-1)]\right\}-1\left(n_{i}\right.$ is the number of values larger than $i$ th value in the series subsequent to its position in the series of $N$ values). Its expected value in a random series is zero, and its standard deviation $\left(S_{\tau}\right)$ is given by $S_{\tau}=\sqrt{\{(4 N+10) /[9 N(N-1)]\}}$. The ratio of $\tau-S_{\tau}$ is considered as an indication of a possible trend in the data. For no trend in the data series, this value lies within the limits of \pm 1.96 at the $5 \%$ level of significance (Hirsch and Slack 1984).

\section{Theoretical background of the Hershfield method}

The Hershfield technique for estimating PMP is an adapted version of Chow (1951) for the frequency analysis of rainfall. Chow (1951) suggested the following formula for most frequency distributions applicable for hydrological analysis:

$X_{t}=\bar{X}_{n}+K_{t} S_{n}$

where $X_{t}$ is the annual maximum rainfall for the return period of $t$ years, $\bar{X}_{n}$ and $S_{n}$ is the mean and standard deviation of the annual maxima of size $n$, respectively and $K_{t}$ is the frequency factor depending only on $t$ and the frequency distribution fitting extreme values of hydrologic data (Chow 1951).

Hershfield (1961, 1965) considered that for the PMP estimation, there is a value of the frequency factor which will not be exceeded, say $K_{\mathrm{m}}$, and he used Chow's equation in a modified form as:

$X_{\mathrm{pmp}}=\bar{X}_{n}+K_{m} S_{n}$

where $X_{\mathrm{PMP}}$ is the PMP rainfall for a given station for specific duration, $\bar{X}_{n}$ and $S_{n}$, respectively, are the mean and standard deviation of the annual maxima, and $K_{\mathrm{m}}$ is the frequency which is considered to be 15 . This value may not be suitable for different stations under different climatic conditions.

\section{Statistical estimation of $\mathrm{PMP}_{24}$}

World meteorological organization modified Hershfield method and introduced it as a manual for estimation of PMP, in this approach (a) $K_{\mathrm{m}}$ is estimated according to $\bar{X}_{n}$, (b) the highest observed data is excluded, and $\bar{X}_{n-1}$ and $S_{n-1}$ are calculated, (c) the correction factors for $\bar{X}_{n}$ and $S_{n}$ is estimated using $\bar{X}_{n}, S_{n}, \bar{X}_{n-1}$, and $S_{n-1}$, (d) by considering the data length another correction factor for $\bar{X}_{n}$ and $S_{n}$ is estimated, (e) $\bar{X}_{n}$ and $S_{n}$ are adjusted, (f) $X_{\mathrm{PMP}}$ is calculated (W.M.O. 1986). In this paper, the recent method is named as Hershfield 1 approach.
Desa et al. (2001) used this formula for calculating $K_{\mathrm{m}}$ :

$K_{m}=\left(X_{1}-\bar{X}_{n-1}\right) / S_{n-1}$

where $X_{1}$ is the highest observed annual maximum rainfall in the series, and $\bar{X}_{n-1}$ and $S_{n-1}$ are the mean and standard deviation of the annual maximum, respectively, when the highest value is excluded in calculating the parameters (Desa et al. 2001). By applying Eqs. (3) and (2), $K_{\mathrm{m}}$ and the corresponding 1-day PMP value was determined, respectively. The so-called method is named as Hershfield 2 approach.

\section{Theoretical background of the multi-station method}

Annual maximum 1-day precipitation $\left(P_{24}\right)$ is usually considered to be an independent identically distributed (i.i.d.) stochastic variable. An i.i.d. may have any distribution function, and the maximum will be distributed according to the extreme value distribution function to whose domain of attraction it belongs (Leadbetter et al. 1983). The most commonly applied extreme value distribution function is type 1 (EV1), or the Gumbel, distribution. EV1 is in its own domain of attraction, therefore, both the i.i.d. and its maximum will be asymptotically distributed according to EV1, when this distribution function is used. The distribution function for annual maxima of individual meteorological stations will often follow the EV1 very closely in the medium-range of values, but it deviates from it for the highest and lowest return periods. These deviations and EV1's lack of an upper limit complicate the use of this distribution function in estimating PMP values (Eliasson 1997). This problem may be solved using a transformed distribution function (TDF) and cut-off distribution function (ODF), both derived from the basic distribution function (BDF) EV1. They are defined as follows (Eliasson 1997):

$\mathrm{BDF}: F(z)=\exp [-\exp (-z)]$

$\mathrm{TDF}: F(z)=\exp \left[-\exp \left(-z+\frac{k}{y_{\lim }-z}\right)\right]$

ODF : $\begin{array}{cl}F(z)=\exp [-\exp (-z)] ; & z<y_{\lim } \text { and } \\ F(z)=1 & z \geq y_{\text {lim }}\end{array}$

$z=\frac{x}{a}+m, y_{\lim }=\frac{x_{P M P}}{a}+m$

where $y_{\lim }$ is limiting reduced variate, $a$ is scale parameter, $m$ is location parameter, $k$ is a negative constant and $x_{\mathrm{PMP}}$ is Index for probable maximum. The ODF is the limit of the TDF when $k \rightarrow 0$. It belongs to the domain of attraction of EV1 (Eliasson 1997).

In this paper, it will be assumed that annual maximum precipitation is an i.i.d. variable $X$. 
We further assume:

(I): the distribution function is a TDF, (II): $y_{\lim }>9$ and (III): $k>-1$.

If assumption (I) is true, the annual maximum data for each station are distributed according to (4). In an EV1 plot, the data will follow the BDF up to a certain point that depends on the value of $k$ and $y_{\text {lim }}$, and there it will deviate from the EV1 line in the direction of higher $y$ values. To see this trend in one station, we need more observation years than are available in one meteorological station. This difficulty may be overcome by regional pooling of data. Data from different meteorological stations have different means and standard deviations. The following standardisation is used to deal with these differences:

$\mu=\left(x_{i}-\bar{X}_{i}\right) / S_{i}$

$\bar{X}_{i}$ estimated mean of annual maxima at station $i, S_{i}$ estimated standard deviation at station $i, \mu$ standardised annual maxima.

Using this standardisation, the estimated BDF is the same for all stations as long as it is a two parameter EV1 distribution function because all stations are now with an estimated zero mean and a standard deviation of one. The BDF does not have to be EV1 as stated in assumption I, but if it is, the pooled standardised data will plot on a line in an EV1 plot, and the line will be straight apart from the previously mentioned deviations that depend on the value of $k$ and $y_{\text {lim }}$ (Eliasson 1997).

If assumption (II) holds, first and second moments will be almost identical for the ODF and the BDF, therefore, estimates of scale and location parameters can be made without knowing the limiting reduced variate. If this assumption holds, we can use the model without a regional estimate of the limiting reduced variate. We do not have to use its value except in PMP estimates, and in this case, an envelope curve may be used to define the probable maximum value, as is done in the Hershfield and NERC methods. Using ODF instead of BDF has the advantage that ODF has the upper limit that BDF does not have (Eliasson 1997).

If assumption (III) holds, the difference between ODF and TDF will be so small that the estimates of scale and location parameters in the TDF can be made without knowing the actual value of $k$ (Eliasson 1997). To summarise, if assumptions I-III holds, we can standardise the annual maxima for each station with its estimated mean and standard deviation.

The cumulative density function for EV1 is:

$F(x)=\exp [-\exp (-y)], \quad$ where $\quad y=(x-m) / a$

The parameters $a$ and $m$ are scale and location parameters. We used the method of moments (MOM) to estimate the parameters by $a=0.7797 S$ and $m=\bar{x}-0.45 S$ where $S$ is the standard deviation of data and $\bar{x}$ is the mean of the data (Eliasson 1997).

\section{$y_{\lim }$ and $\mathrm{PMP}_{24}$ calculation}

From NERC report (1975) it is possible to derive the following relation for $y_{\text {lim }}$ :

$y_{\lim }=10.7-0.0071 P_{5} \quad 25<P_{5}<200 \mathrm{~mm} /$ day

where $P_{5}$ is defined as the maximum annual precipitation with return period of 5 years. The ODF may now be written as follows:

$x=p_{5}\left[1+C_{i}\left(y_{i}-1.5\right)\right] y_{i}<y_{\lim }$

$x=x_{P M P} \quad y_{i} \geq y_{\text {lim }}$

The simplest way to derive (Eq. 10) is to take the double logarithm of the ODF (Eq. 6), write down the $P_{5}$ value and subtract it from the formula for $x$. The coefficient $C_{i}$ may be denoted as the slope coefficient because it is a dimensionless slope of the line (Eq. 10) in a $x / P_{5^{-}} y$ plot. Each station brings about one value of $C_{i}$. Now Eq. 10 contains the two parameters $P_{5}$ and $C_{i}$. The mean and the standard deviation may be used instead, and $P_{5}$ and $C_{i}$ calculated in terms of these parameters. Doing so $C_{i}$ becomes (Eliasson 1997):

$C_{i}=0.78 S_{i} /\left(\bar{X}_{i}+0.72 S_{i}\right)$

$\bar{X}_{i}$ average at station $i, S_{i}$ standard deviation at station $i$.

While $y_{\text {lim }}$ is a regional parameter, both $P_{5}$ and $C_{i}$ are local parameters playing the same role of the average and the coefficient of variation in Hershfield 1 approach.

In each station, we can estimate the PMP value using Eq. 10 and inserting the local $C_{i}$ value and $y_{\text {lim }}$. At station i we will have:

$x_{i}=p_{5}\left[1+C_{i}\left(y_{\mathrm{lim}}-1.5\right)\right]$

According to assumption (I) there is no higher $x$ value possible at point $i$. Therefore, this value is the PMP value at this particular location $i$. However, a higher PMP value in the region as a whole may exist. We seek the maximum $x$ in the region remembering that $y_{\text {lim }}$ is the same in all points (or stations).

$$
\begin{aligned}
\mathrm{PMP} & =\operatorname{Max}\left\{x_{i}\right\}=\operatorname{Max}\left\{P_{5}\left[1+C_{i}\left(y_{\text {lim }}-1.5\right)\right]\right\} \\
& =\operatorname{Max}\left(P_{5}\right)\left[1+\operatorname{Max}\left\{C_{i}\right\}\left(y_{\lim }-1.5\right)\right]
\end{aligned}
$$

Using a guideline length of 5-30 km between independent stations (Buishand 1984), in the $P_{5}$ range of $25-200 \mathrm{~mm}$, the distribution of the $\operatorname{Max}\left\{C_{i}\right\}$ may be calculated by Eliasson (1997):

$\operatorname{Max}\left\{C_{i}\right\}=\bar{C}_{i}+\operatorname{Ln}\left(N_{\mathrm{s}} S C_{i} / C\right)$ 
Table 2 Frequency distribution of $K_{\mathrm{m}}$ values for Hershfield 1 approach

\begin{tabular}{lllll}
\hline$K_{\mathrm{m}}$ & $<17.9$ & $17.9-18.2$ & $18.2-18.5$ & $>18.5$ \\
\hline Frequency & 1 & 7 & 22 & 9 \\
\hline
\end{tabular}

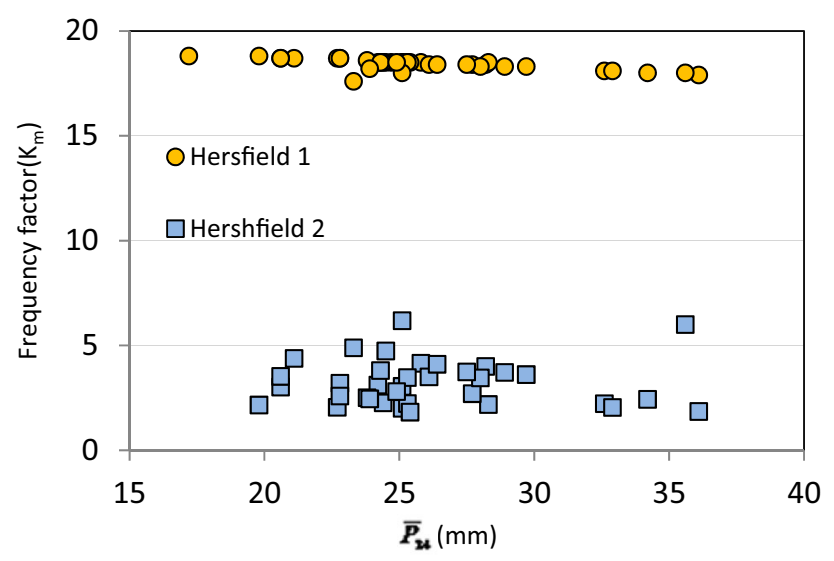

Fig. 2 The plot of $K_{\mathrm{m}}$ versus $\bar{P}_{24}$ for Hershfield 1 and Hershfield 2 approaches

$\operatorname{Max}\left\{C_{i}\right\}$ expected value of the highest $C_{i}$ in the region, $\bar{C}_{i}$ estimated average $C_{i}$ value for the region, $S C_{\mathrm{i}}$ estimated standard deviation of $C_{i}$ values in the region, $\mathrm{N}_{s}$ number of stations, $C=1 / a$, $a$ theoretical value of the EV1 scale parameter for pooled data $(C=1.283)$.

\section{Results}

Data were thoroughly checked, and any doubtful observations were eliminated. The homogeneity of all 39 stations was checked by non-parametric Mann-Kendall rank test. The ratio of $\tau / S_{\tau}$ for three stations of Radkan (station no. 2,
Table 1), Dolat-Abad (station no. 16), Incheh-Olya (station no. 26) were 2.3, 4.4 and 3.9, respectively; hence, these heterogeneous stations were discarded.

\section{Hershfield 1 approach}

To estimate PMP; 1-day annual maximum rainfall values of 36 stations were analyzed and for each station the values of $\bar{X}_{n-1}, \bar{X}_{n}, S_{n}, S_{n-1}$ and the coefficient of variability $\left(C_{V}=S_{n} / \bar{X}_{n}\right)$ were calculated. The range of $K_{\mathrm{m}}$ and PMP values was 17.6-18.8 and 128.2-284.2 mm (Tables 2, 4; Fig. 2), respectively. $K_{\mathrm{m}}, \mathrm{PMP}_{24}$ and $P_{24}$ are affected by location and cannot be used as a comparative factor, but the ratio of $P M P_{24} / P_{24}$ is shown to facilitate comparisons for different stations (Desa et al. 2001; Desa and Rakhecha 2007; Ghahreman 2008). The so-called ratio varied between 2.54 and 6.77 (Table 4; Fig. 3); the partially wide range of $P M P_{24} / P_{24}$ is in part influenced by short record length of the stations.

\section{Hershfield 2 approach}

In this method, Eqs. (3) and (2) were applied to $K_{\mathrm{m}}$ and PMP calculation. The results are summarized in Table 4 . As shown, the values of $K_{\mathrm{m}}$ varied between 1.82 and 6.18 (Tables 3, 4; Fig. 2), with the latter being the upper limit of the estimated $K_{\mathrm{m}}$. As PMP deals with unusual rainfall values, the corresponding frequency factor must also be chosen from the extremely high values. For the study area, $K_{\mathrm{m}}$ would be 6.18 (the maximum value of $K_{\mathrm{m}}$ for Hershfield 2 approach-Table 4$)$. Using $K_{\mathrm{m}}$ of 6.18 , the mean $\left(\bar{X}_{n}\right)$ and standard deviation $\left(S_{n}\right)$ for each station, PMP values for a 1-day duration for all stations were computed using Eq. (2). An average factor of 1.13 (Tomlinson 1980) was used to convert 1-day PMP estimates into 24-h PMP. Values of estimated $\mathrm{PMP}_{24}$ were between 62.7 and $160.2 \mathrm{~mm}$, and the ratio of $P M P_{24} / P_{24}$ varied between 1.50 and 2.72 (Table 4; Fig. 3) which was in harmony with Desa et al.

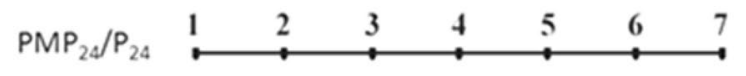

Current study; Hershfield 1 method

Current study; Hershfield 2 method

Current study; Multi-station method

Desa et al.(2001): Hershfield 2 method in the west of Malaysia

Desa and Rakhecha (2007); Hershfield 1 method in the south of Malaysia

Ghahraman (2008); Hershfield 1 method in the north east of Iran

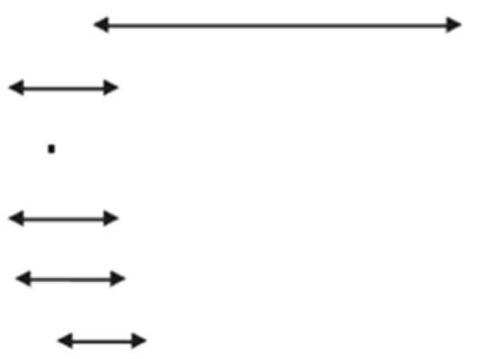

Fig. 3 The ratio of $P M P_{24}-P_{24}$ for different studies 
Table 3 Frequency distribution of $K_{\mathrm{m}}$ values for Hershfield 2 approach

\begin{tabular}{lllllllll}
\hline$K_{\mathrm{m}}$ & $2.4>$ & $2.4-3$ & $3-3.6$ & $3.6-4.2$ & $4.2-4.8$ & $4.8-5.4$ & $5.4-6$ & $6<$ \\
\hline Frequency & 10 & 6 & 8 & 7 & 2 & 1 & 1 & 1 \\
\hline
\end{tabular}

Table $4 P M P_{24}$ by different approaches

\begin{tabular}{|c|c|c|c|c|c|c|c|c|c|c|}
\hline \multirow{2}{*}{$\begin{array}{l}\text { Method } \\
\text { Station number }\end{array}$} & \multicolumn{3}{|c|}{ Hershfield 1 approach } & \multicolumn{3}{|c|}{ Hershfield 2 approach } & \multicolumn{4}{|c|}{ Multi-Station approach } \\
\hline & $K_{\mathrm{m}}$ & $\mathrm{PMP}_{24}(\mathrm{~mm})$ & $\mathrm{PMP}_{24} / \mathrm{P}_{24}$ & $K_{\mathrm{m}}$ & $\mathrm{PMP}_{24}(\mathrm{~mm})$ & $\mathrm{PMP}_{24} / \mathrm{P}_{24}$ & $\mathrm{~m}$ & a & $\mathrm{P}_{5}(\mathrm{~mm})$ & $\mathrm{C}_{\mathrm{i}}$ \\
\hline 1 & 18.5 & 200.1 & 4.00 & 3.05 & 94.9 & 1.90 & 20.89 & 7.30 & 31.8 & 0.2293 \\
\hline 3 & 18.5 & 207.3 & 3.57 & 4.15 & 100.9 & 1.74 & 21.18 & 8.01 & 33.2 & 0.2413 \\
\hline 4 & 18.4 & 212.0 & 3.42 & 4.00 & 106.6 & 1.72 & 23.38 & 8.35 & 35.9 & 0.2326 \\
\hline 5 & 17.6 & 143.6 & 2.93 & 4.89 & 78.7 & 1.61 & 19.93 & 5.84 & 28.7 & 0.2036 \\
\hline 6 & 17.9 & 284.2 & 5.07 & 1.85 & 126.5 & 2.26 & 30.58 & 9.57 & 44.9 & 0.2130 \\
\hline 7 & 18.5 & 172.6 & 4.41 & 2.00 & 80.9 & 2.07 & 21.72 & 5.86 & 30.5 & 0.1922 \\
\hline 8 & 18.5 & 208.1 & 4.16 & 3.11 & 94.5 & 1.89 & 19.88 & 7.49 & 31.1 & 0.2409 \\
\hline 9 & 18.1 & 233.2 & 4.24 & 2.22 & 111.6 & 2.03 & 27.78 & 8.35 & 40.3 & 0.2072 \\
\hline 10 & 18.7 & 211.2 & 4.22 & 3.20 & 95.6 & 1.91 & 18.30 & 7.80 & 30.0 & 0.2600 \\
\hline 11 & 18.7 & 167.6 & 4.77 & 2.05 & 73.8 & 2.11 & 19.60 & 5.38 & 27.7 & 0.1945 \\
\hline 12 & 18.5 & 198.0 & 3.30 & 4.74 & 106.8 & 1.78 & 19.40 & 8.83 & 32.6 & 0.2706 \\
\hline 13 & 18.5 & 200.2 & 4.26 & 2.18 & 97.9 & 2.08 & 24.05 & 7.36 & 35.1 & 0.2098 \\
\hline 14 & 18.5 & 182.0 & 4.44 & 2.26 & 84.7 & 2.06 & 20.72 & 6.38 & 30.3 & 0.2106 \\
\hline 15 & 18.7 & 191.0 & 3.90 & 4.38 & 91.0 & 1.86 & 16.55 & 7.89 & 28.4 & 0.2781 \\
\hline 17 & 18.1 & 184.0 & 3.91 & 2.04 & 89.6 & 1.91 & 29.52 & 5.86 & 38.3 & 0.1529 \\
\hline 18 & 18.7 & 170.0 & 4.25 & 3.02 & 75.3 & 1.88 & 17.24 & 5.82 & 26.0 & 0.2240 \\
\hline 19 & 18.4 & 188.0 & 4.18 & 2.70 & 88.1 & 1.96 & 24.04 & 6.35 & 33.6 & 0.1892 \\
\hline 20 & 18.8 & 150.0 & 5.00 & 2.16 & 62.7 & 2.09 & 17.20 & 4.50 & 23.9 & 0.1879 \\
\hline 21 & 18.3 & 227.0 & 3.98 & 3.61 & 109.3 & 1.92 & 24.58 & 8.87 & 37.9 & 0.2341 \\
\hline 22 & 18.4 & 197.0 & 3.65 & 3.50 & 110.3 & 2.04 & 20.40 & 9.88 & 35.2 & 0.2806 \\
\hline 23 & 18.5 & 175.0 & 4.27 & 2.23 & 82.3 & 2.01 & 21.84 & 5.99 & 30.8 & 0.1943 \\
\hline 24 & 18.7 & 209.2 & 4.64 & 2.59 & 92.5 & 2.06 & 18.50 & 7.45 & 29.7 & 0.2510 \\
\hline 25 & 18.5 & 146.0 & 4.17 & 1.82 & 69.9 & 2.00 & 22.74 & 4.61 & 29.7 & 0.1554 \\
\hline 27 & 18.5 & 189.5 & 3.79 & 3.47 & 91.8 & 1.84 & 21.23 & 7.05 & 31.8 & 0.2217 \\
\hline 28 & 18.6 & 140.0 & 4.00 & 2.51 & 63.5 & 1.81 & 21.44 & 4.09 & 27.6 & 0.1485 \\
\hline 29 & 18.3 & 180.0 & 3.53 & 3.71 & 84.1 & 1.65 & 25.58 & 5.75 & 34.2 & 0.1681 \\
\hline 30 & 18.4 & 264.0 & 6.77 & 4.10 & 105.9 & 2.72 & 21.51 & 8.47 & 34.2 & 0.2475 \\
\hline 31 & 18.0 & 152.4 & 2.54 & 6.18 & 89.7 & 1.50 & 21.70 & 5.85 & 31.5 & 0.1918 \\
\hline 32 & 18.5 & 159.0 & 3.38 & 3.80 & 83.4 & 1.77 & 20.69 & 6.17 & 29.9 & 0.2076 \\
\hline 33 & 18.5 & 190.0 & 4.13 & 2.80 & 88.1 & 1.92 & 21.02 & 6.63 & 31.0 & 0.2159 \\
\hline 34 & 18.3 & 222.0 & 4.19 & 3.45 & 92.1 & 1.74 & 23.41 & 7.96 & 35.4 & 0.2253 \\
\hline 35 & 18.0 & 277.0 & 4.40 & 6.00 & 160.2 & 2.54 & 27.87 & 13.40 & 43.5 & 0.2794 \\
\hline 36 & 18.4 & 162.0 & 3.24 & 3.74 & 83.6 & 1.67 & 24.10 & 5.89 & 32.9 & 0.1790 \\
\hline 37 & 18.0 & 272.0 & 4.69 & 2.43 & 117.1 & 2.02 & 29.04 & 8.76 & 42.2 & 0.2078 \\
\hline 38 & 18.2 & 178.4 & 4.35 & 2.45 & 72.2 & 1.76 & 20.45 & 5.98 & 29.4 & 0.2033 \\
\hline 39 & 18.7 & 186.0 & 4.13 & 3.52 & 72.3 & 1.61 & 16.83 & 6.53 & 26.6 & 0.2454 \\
\hline
\end{tabular}

(2001), Desa and Rakhecha (2007) and Ghahreman (2008) studies (Fig. 3).

\section{Multi-station method}

$P_{5}$ and $C_{i}$ factors were calculated after computing method of moment parameters ( $\mathrm{a}$ and $\mathrm{m}$ ), results are shown in Table 4, $C_{i}$ values range between 0.1485 and 0.2806 . The $C_{i}$ station values in Fig. 4 seem to cluster around the average value 


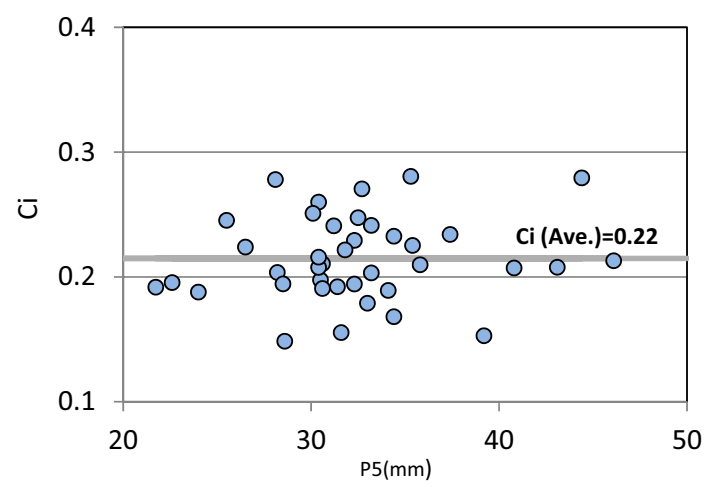

Fig. 4 The plot of $C_{i}$ versus $P_{5}$

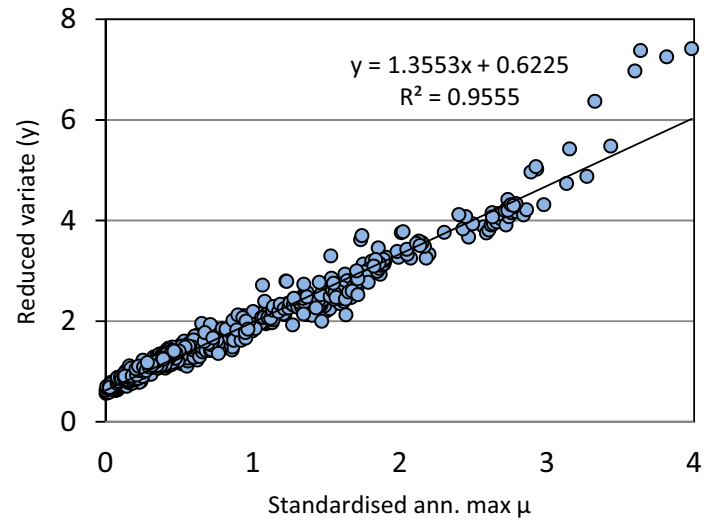

Fig. 5 EV1 plot of 500 values in the study area

and lack a specific pattern. This verifies the homogeneity of the stations. Standardised data were pooled. There are 1103 points altogether, and the 500 highest points are shown (Fig. 5). As shown the data follow the EV1 up to a certain point $(y=3)$ and there it will deviate from the EV1 line in the direction of higher $y$ values. Finally, $y_{\text {lim }}, \operatorname{Max}\left\{C_{i}\right\}$ and $\mathrm{PMP}_{24}$ were calculated 10.4, 0.20 and $124 \mathrm{~mm}$, respectively.

Ghahreman (2008) analyzed yearly maximum 1-day rainfall data of 20-36 years for 30 stations in the Atrak watershed region in the northeast of Iran to estimate $\mathrm{PMP}_{24}$ based on Hershfield 2 approach. The highest value of $K_{\mathrm{m}}$ was found to be $9.63, \mathrm{PMP}_{24}$ over the Atrak watershed ranged from 97 to $295 \mathrm{~mm}$ and the ratio of $P M P_{24} / P_{24}$ was between 1.95 and 3.01 (Ghahreman 2008). The result of Ghahreman analysis is in harmony with Hershfield 2 approach in the current study. However, such variations between the two results may be due to the differences observed in the climatic conditions and shorter record length in Ghahreman's study. In
2001, Desa et al. analyzed yearly maximum 1-day rainfall data of 30-60 years for 33 stations over Selangor in western Malaysia to estimate $\mathrm{PMP}_{24}$ by Hershfield 2 approaches. $K_{\mathrm{m}}$ and $\mathrm{PMP}_{24}$ were found between 2 and 8.7 and $375-500 \mathrm{~mm}$, respectively, which were higher than the current study, such variations between two researches may originate from the difference in climatic conditions, and longer record length in Desa's study. Nevertheless, the ratio of $P M P_{24} / P_{24}$ was equal between the two studies. Desa and Rackham (2007) used Hershfield 2 approach in southern Malaysia, $K_{\mathrm{m}}$ and $\mathrm{PMP}_{24}$ were obtained between 1.1 and 8 and 373-1209 mm, respectively (Desa and Rakhecha 2007). The higher PMP was calculated than Desa et al. (2001) study may be due to the differences in the climate, but the $K_{\mathrm{m}}$ was approximately equal.

Serious attempts were made to find a relation between $\mathrm{PMP}_{24}$ (by Hershfield 1 and Hershfield 2 approaches) and characteristics of the meteorological stations like height, data length, geographic characteristics, etc., but unfortunately no trend was found. In Hershfield 1 and Hershfield 2 approaches, we can claim that if we select just the $\mathrm{PMP}_{24}$ of one station, it is possible to have grater values for other points while in multi-station method, a common value is being yield for $\mathrm{PMP}_{24}$ which is because of using a combination of data from all stations.

The map of PMP24 was prepared for both approaches of Hershfield (Fig. 6). For both approaches, the high $\mathrm{PMP}_{24}$ values generally can be seen in the south and the southwest, and the low values can be seen in the east and the northwest of the study area (Fig. 6).

\section{Conclusion}

The main purpose of this study was to introduce a simple standardized method of $\mathrm{PMP}_{24}$ computation using multistation method and two approaches of Hershfield technique for stations in the northeast of Iran. Due to record lengths, there is a high fluctuation in calculated data of Hershfield 1 approach. The so-called problem was adjusted by Hershfield 2 approach, in which the PMP range was approximately half of the Hershfield 1. The ratio of $P M P_{24} / P_{24}$ was consistent and was in harmony with the multi-station value. Multistation and Hershfield 2 methods could be recommended for other regions. However, future records may be needed to verify the ensuing results of $\mathrm{PMP}_{24}$ and the corresponding resulted probable maximum flood (PMF) values. 

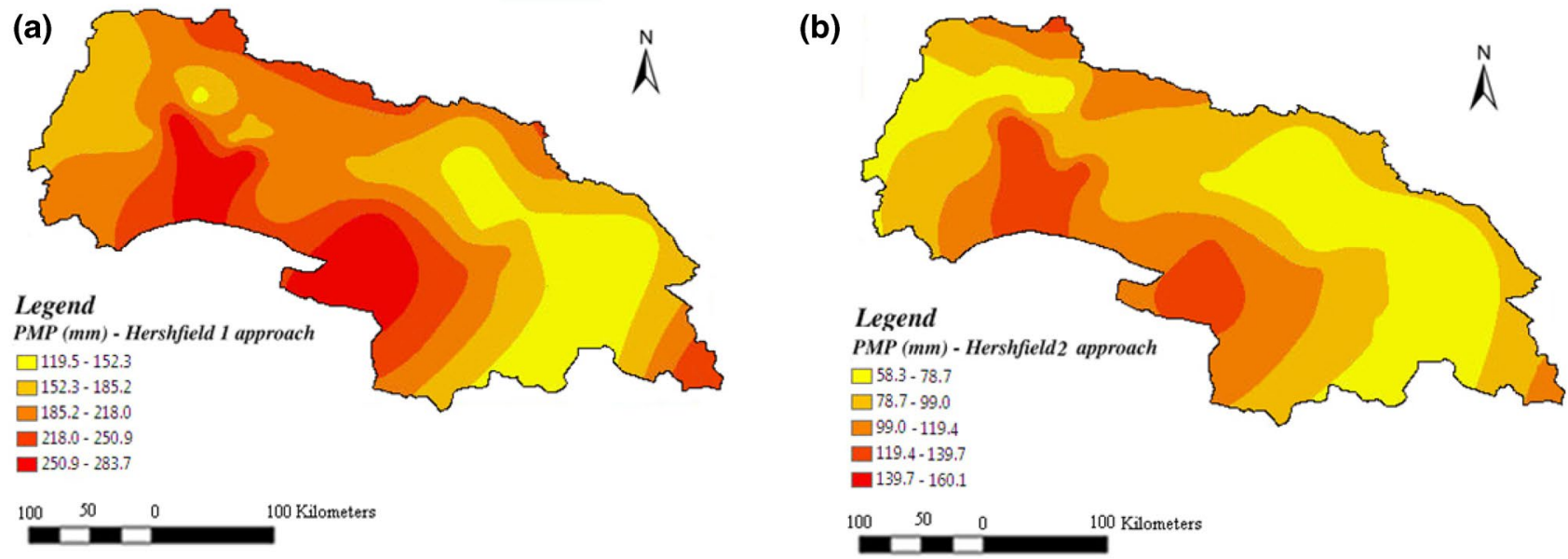

Fig. 6 The map of $\mathrm{PMP}_{24}$ in the northeast of Iran according to a Hershfield 1 approach and $\mathbf{b}$ Hershfield 2 approach

\section{References}

Buishand TA (1984) Bivariate extreme value data and the stationyear method. J Hydrol 69:77-95. https://doi.org/10.1016/00221694(84)90157-4

Casas MC, Rodríguez M, Prohom M, Gázquez A, Redaño A (2011) Estimation of the probable maximum precipitation in Barcelona (Spain). Int J Climatol 31(9):1322-1327. https://doi.org/10.1002/ joc. 2149

Chow VT (1951) A general formula for hydrologic frequency analysis. Trans Am Geophys Union 32(2):231-237. https://doi.org/10.1029/ TR032i002p00231

Desa MN, Rakhecha PR (2007) Probable maximum precipitation for 24-h duration over an equatorial region. Part 2-Johor, Malaysia. J Atmos Res 84(1):84-90. https://doi.org/10.1016/j.atmos res.2006.06.005

Desa MN, Noriah AB, Rakhecha PR (2001) Probable maximum precipitation for 24-h duration over Southeast Asia monsoon region-Selangor Malaysia. J Atmos Res 58(1):41-54. https://doi. org/10.1016/S0169-8095(01)00070-9

Eliasson J (1997) A statistical model for extreme precipitation. J Water Resour Res 33(3):449-455. https://doi.org/10.1029/96WR03531

Federal Energy Regulatory Commission (FERC) (2001) Engineering guidelines, Chapter VIII. Determination of the probable maximum flood. Washington, DC

Ghahraman B (2008) The estimation of one day duration probable maximum precipitation over Atrak watershed in Iran. Iran J Sci Techol 32(2):175-179. https://doi.org/10.22099/IJSTC.2008.722

Ghahraman B, Khalili D (2004) A re-visit to partial duration series of short duration rainfalls. Iran J Sci Technol 28(5):547-558. https ://doi.org/10.22099/IJSTC.2013.1107. dio

Hershfield DM (1961) Estimating the probable maximum precipitation. J Hydrol Div ASCE 78(5):99-116

Hershfield DM (1965) Method for estimating probable maximum rainfall. J Am Water Works Assoc 57(8):965-972

Hirsch R, Slack J (1984) A nonparametric trend test for seasonal data with serial dependence. J Water Resour Res 20(16):727-732. https ://doi.org/10.1029/WR020i006p00727

Hufman K, Schaefer M, Bowles D (2014) Local precipitation-frequency studies development of 1-hour/1-square mile precipitation-frequency relationships for two example nuclear power plant sites. Electric Power Research Institute, Palo Alto, p 3002004400
Koutsoyainnis D (1999) A probabilistic view of Hershfield's method for estimating probable maximum precipitation. J Water Resour Res 35(4):1313-1322. https://doi.org/10.1029/1999WR900002

Kunkel KE, Karl TR, Easterling DR, Redmond K, Young J, Yin XAND, Hennon P (2013) Probable maximum precipitation and climate change. Geophys Res Lett 40(7):1402-1408. https://doi. org/10.1002/grl.50334

Leadbetter MR, Lindgren G, Rootzen H (1983) Extremes and related properties of random sequences and processes. Springer, Berlin

Mitchell JM Jr, Dzerdzeevskii B, Flohn H, Hofmeyr WL, Lamb HH, Rao KN, Wallen CC (1966) Climatic change. WMO Technical Note No 79. World Meteorological Organization, Geneva,p 79

Nathan R, Jordan P, Scorah M, Lang S, Kuczera G, Schaefer M, Weinmann E (2016) Estimating the exceedance probability of extreme rainfalls up to the probable maximum precipitation. J Hydrol 543:706-720. https://doi.org/10.1016/j.jhydrol.2016.10.044

NERC (1975) Hydrological studies, Flood Studies Report vol, II. Natural Environment Research Council, London

NOTE: Heterogeneous stations by Mann-Kendall rank test were discarded (station no and 26)

Prasad R, Hibler LF, Coleman AM, Ward DL (2011) Design-basis flood estimation for site characterization at nuclear power plants in the United States of America No. PNNL-20091; NUREG/CR-7046. Pacific Northwest National Laboratory (PNNL), Richland

Rastogi D, Kao S, Ashfaq M, Mei R, Kabela ED, Gangrade S, Naz BS, Preston BL, Singh N, Anantharaj VG (2017) Effects of climate change on probable maximum precipitation: a sensitivity study over the Alabama-Coosa-Tallapoosa River Basin. J Geophys Res Atm 122(9):4808-4828. https://doi.org/10.1002/2016JD026001

Rouhani H, Leconte R (2016) A novel method to estimate the maximization ratio of the Probable Maximum Precipitation (PMP) using regional climate model output. J Water Resour Res 52(9):73477365. https://doi.org/10.1002/2016WR018603

Tomlinson AI (1980) The frequency of high intensity rainfalls in NewZealand, part I. Water and Soil Technical Publication. National Water and Soil Conservation, Wellington, p 36

World Meteorological Organisation (WMO) (1986) Manual for estimation of probable maximum precipitation. In: Operational hydrology report. seconded. Publication No, 332, WMO, Geneva, Switzerland 